\title{
Foto-memórias de tempos difíceis ${ }^{*}$
}

\section{Hard times photo-memories}

\author{
Annateresa Fabris \\ Bacharel licenciada em História (FFLCH/USP), mestre e doutora em Artes (ECA/USP) \\ e professora titular aposentada da ECA/USP \\ neapolis@ig.com.br
}

\section{Resumo:}

Em 1936, a revista Fortune encomendou a James Agee uma reportagem sobre a pobreza rural no Sul dos Estados Unidos. A delonga do escritor e as dúvidas da revista sobre o projeto determinaram o cancelamento da publicação. O projeto foi publicado sob a forma de livro em 1941 - Elogiemos os Homens Ilustres -, com um bloco de trinta e uma fotos de Evans destituídas de legendas antecedendo o texto lírico de Agee. Como este enfatizou, fotos e texto eram "coiguais, mutuamente independentes e plenamente colaborativos".

Palavras-chave: Fotografia; Documento; Literatura

\section{Abstract:}

In 1936 Fortune magazine asked James Agee to write a report on rural poverty in the South of the United States. The writer's procrastination and Fortune's doubts about the project prompted the magazine to cancel the publication. The project was published as a book in 1941 - Let Us Now Praise Famous Men -, with a block of thirty-one Evans uncaptioned photographs preceding Agee's lyrical text. As the writer stressed, photographs and text were to be viewed as "coequal, mutually independent, and fully collaborative".

Keywords: Photography; Document; Litterature

* Trabalho apresentado no GT Memória e Fotografia 


\section{Artigos \& Ensaios}

1 - Exemplos dos "roteiros de imagens" concebidos por Stryker foram reproduzidos no livro de Geoff Dyer (2008: 13-14). primeiro encontro de Walker Evans com Fred Ricketts, um dos agricultores cuja vida será abordada em Elogiemos os Homens Ilustres, é vivamente evocado por James Agee no texto publicado em 1941. Enquanto conversava com o colono, cujo nome verdadeiro era Frank Tingle, na saída do tribunal do condado de Hale (Alabama), Evans tirou uma dúzia de fotos, atraindo a atenção dos outros dois protagonistas da reportagem: o meeiro George Gudger (Floyd Burroughs) e o colono Bud Woods (Bud Fields). Acreditando que Evans e Agee eram funcionários do governo que poderiam ajudá-lo na difícil conjuntura vivida pelos agricultores na década de 1930, Ricketts os leva até sua casa. Lá o fotógrafo realiza uma nova sessáo de retratos, apresentada por Agee como um ato de crueldade. O escritor descreve a cólera/resignação da esposa de Ricketts, a quem atribui a percepção da sessão fotográfica como uma maneira de pôr a nu a pobreza da família "diante da fria absorção da câmera". Evans, "recurvo sob capa e cobertura de cruel tecido, e girando botóes", não chega a ensaiar nenhum tipo de negociação com seus modelos. Ao contrário, fotografa seus preparativos para a pose, enquanto eles acreditavam estar realizando um teste (AGEE, 2009: 337-340).

A família de Gudger, igualmente convocada, tem tempo de compor uma imagem mais condizente com a solenidade do retrato, apesar da precariedade das roupas. Sabedor da tradição do gênero, o meeiro negocia com Evans o local da tomada. Após ter descartado a lateral do imóvel de Ricketts, "onde tudo é estragado e feio", escolhe como fundo "um arbusto alto descabelado em flores, na frente da casa em pleno sol duro". Se bem que náo haja nenhuma descrição de sua atuação diante da câmera, também a família de Woods é convidada para a sessão de pose na casa de Ricketts, a quem, dias depois, o fotógrafo e o repórter manifestam o próprio pesar pelo modo como esta havia sido realizada: colocando a esposa e as crianças em fila e "tirando retratos sem dar qualquer explicação a ela” (AGEE, 2009: 342-344, 359).

Encomendado pela revista Fortune em 1936, o artigo, que dará origem a Elogiemos os Homens Ilustres, tinha como objetivo proporcionar "um registro fotográfico e verbal da vida e do ambiente cotidianos de uma típica família de colonos brancos" do Sul dos Estados Unidos (AGEE, 2009: 11). Para o registro fotográfico, Agee convida Evans, que já havia colaborado com a revista em 1934, ao publicar sete fotografias num artigo dedicado ao Partido Comunista. O fotógrafo solicita uma licença da Seção Histórica da Farm Security Administration (FSA), para a qual estava trabalhando desde o outono de 1935.

Concebida por Roy E. Stryker, professor do departamento de Economia da Universidade Columbia, a Seção Histórica contrata uma equipe de fotógrafos (John Vachon, Ben Shahn, Russell Lee, Dorothea Lange, Jack Delano, Arthur Rothstein, Carl Mydans, Marion Post Wolcott, John Collier Jr., Gordon Parks, Theodor Jung, Walker Evans), a quem cabia documentar a realidade da pobreza causada pela recessão que se seguira ao crash da bolsa de Nova York (outubro de 1929), por meio de imagens emocionais da crise, que não ajudavam a esclarecer suas verdadeiras razóes. Essa estratégia de mostrar e ocultar a um só tempo (MORA e HILL, 2004: 132) a realidade da era Roosevelt não é partilhada por Evans, que opta por trabalhar de maneira independente, de acordo com o próprio ritmo e as próprias concepçôes, sem levar em conta as instruçôes [1] que Stryker dava aos membros da equipe (HAGEN, 1983: s.p.).

Essa mesma independência, alicerçada na ideia de que a fotografia era um "registro puro, não propaganda" (apud: MORA e HILL, 2004: 134), é exibida 
por Evans na colaboração com Agee. Seus métodos de trabalho são diametralmente opostos. Agee entrega-se de corpo e alma à reportagem, que tem a duração de três semanas (julho-agosto de 1936). Dorme no chão da casa dos Gudger. Redige à noite suas observaçóes num estilo livre, lírico e apaixonado, repleto de excessos descritivos e evocativos, por vezes próximo da escrita automática surrealista e não isento, em certas páginas, de uma palpável tensão erótica, provocada pela presença de Emma, cunhada do agricultor.

Evans, ao contrário, comporta-se como um observador que mantém a devida distância em relação ao referente. Admirador da "compreensão lírica da rua" de Eugène Atget, do "processo clínico" de August Sander (EVANS, 2000: 81, 84) e dos retratos nova-iorquinos de Paul Strand, Evans era partidário de uma "edição fotográfica da sociedade", tarefa a que se dedicará com afinco por meio da elaboração de uma metodologia de trabalho precisa, cujos pressupostos eram a objetividade, a clareza e a serializaçáo. Esses elementos, que o levam a privilegiar o distanciamento, a luminosidade, a nitidez e a legibilidade da imagem, são usados, a princípio, na documentação da arquitetura vitoriana da regiáo de Boston (1931). Utilizando uma câmera de grande formato, o fotógrafo lança as bases do que, em oposição à inutilidade da arte, denominará "estilo documentário", baseado em duas características principais: distanciamento e testemunho neutro (CHASSEY, 2005: 75-76).

Se essa concepção é problematizada nos dias de hoje, é ela, no entanto, que atrai a atenção de Agee, para quem a fotografia, "manejada de forma limpa e literal em seus próprios termos, como um gélido, em certos sentidos limitado, em certos sentidos mais capaz, olho", possibilitava "registrar nada que não a verdade absoluta, seca” , do mesmo modo que a gravação fonográfica e os instrumentos científicos (AGEE, 2009: 234).

Os excessos narrativos de Agee, que escreve um artigo dez vezes maior que o combinado e eivado de qualidades negativas aos olhos da redação de Fortune - "pessimista, não construtivo, nada útil, indignado, lírico e sempre pessoal" -, decretam o insucesso da empreitada. Depois de ter tentado cortá-lo ao longo de um ano, os editores da revista devolvem o manuscrito ao autor (SUZUKI Jr., 2009: 439-440). Fundada em fevereiro de 1930 por Henry R. Luce, proprietário do Time Magazine (1923), Fortune tinha como objetivo oferecer "textos claros e legíveis, abundantemente ilustrados, num formato grande, agradável ao olho" (apud: CAMPANY, 2011: 90). O primeiro atributo está, sem dúvida, ausente do texto de Agee, distante das convençóes do jornalismo e interessado táo somente na manifestação de uma visão particular da realidade dos Estados Unidos durante a recessão. Não partilhando os pressupostos de uma experiência que respondia à "estética do capital" (CAMPANY, 2011: 90), o escritor resolve reelaborar e ampliar o relato, o qual, depois de ter sido recusado pela Harper \& Brothers (1939), é finalmente publicado, em 1941, pela Houghton Mifflin, com escasso sucesso de público.

No prefácio, Agee apresenta o livro como um esforço para

reconhecer a estatura de uma parcela da população cuja existência mal se imagina, e conceber técnicas adequadas de registro, comunicaçáo, análise e defesa desse grupo [...] Os instrumentos imediatos são dois: a câmera de instantâneos e a palavra impressa. O instrumento- 
-comandante - que é também um dos centros do tema - é a consciência humana individual e antiautoritária. Por fim, pretende-se que este registro e esta análise sejam exaustivos, sem que nenhum detalhe, por mais que possa parecer trivial, permaneça intocado, ou que seja evitada qualquer relevância que esteja dentro das capacidades da reminiscência manter, da inteligência perceber e de nela o espírito persistir (AGEE, 2009: 12-13).

Desconfiando da capacidade de a palavra conseguir dar conta do real, o escritor auspicia, no começo do livro, uma publicação feita de fotos e de "fragmentos de tecido, um pouco de algodáo, torróes de terra, registros de fala, peças de ferro e madeira, frascos de odores, pratos de comida e de excremento" (AGEE, 2009: 30, 224-227). Se isso não era possível, o livro, contudo, caracteriza-se por uma apresentação inusual, ao confrontar de imediato o leitor com trinta e uma fotografias de Evans, destituídas de legendas. O fotógrafo já havia colaborado anteriormente com escritores de maneira peculiar, ao conceber portfólios fotográficos independentes do texto para The Bridge (1930), de Hart Crane, e The Crime of Cuba (1933), de Carleton Beal. Em Elogiemos os Homens Ilustres, que Evans considera um exemplo de "literatura experimental" (apud: MORA e HILL, 2004: 199), a relação entre texto e imagem é um tanto complexa. Fotógrafo e escritor tratam de demarcar as diferenças existentes entre ambos e, ao mesmo tempo, de integrá-los num conjunto. É o que se depreende do prefácio assinado por Agee, para quem as fotografias "não são ilustrativas. Elas, e o texto são coiguais, mutuamente independentes e plenamente colaborativos" (AGEE, 2009: 13).

A apresentação anticonvencional da colaboração entre Agee e Evans contrastava com os livros sobre o período da recessão publicados pela Seção Histórica da FSA, nos quais os documentos fotográficos eram acompanhados de textos. É o caso de Land of the Free (1938), de Archibald MacLeish; de Home Town: Photographs by the Farm Security Photographers (1940), de Sherwood Anderson; de An American Exodus: a Record of Human Erosion (1939), de Dorothea Lange e do economista Paul Taylor. Centrado na seca ocorrida na região sudoeste em meados dos anos 1930 e na consequente migração dos agricultores, o último título determina o fim da colaboração de Lange com a Seção Histórica, uma vez que Taylor apresentava como simplistas as posturas sociais da FSA. Baseado em depoimentos de agricultores, o empreendimento de Lange/Taylor diferenciava-se do livro-documento mais famoso do período, You Have Seen Their Faces (1937), fruto da colaboração entre o escritor Erskine Caldwell e a fotógrafa Margaret Bourke-White, que se caracterizava pela presença de relatos ficcionais.

Agee demonstra, sem rodeios, sua antipatia pela figura de Bourke-White, ao reproduzir, na parte final de Elogiemos os Homens Ilustres, um artigo publicado no New York Post, em que a fotógrafa era apresentada como uma pessoa frívola e como "uma das mulheres mais bem pagas dos Estados Unidos" (AGEE, 2009: 415). Bourke-White, que colaborava com Fortune desde sua fundação, era uma profissional reputada sobretudo pelas vistas arquitetônicas e pelas imagens de máquinas, fotografadas de acordo com os postulados modernistas, mas o resultado de You Have Seen Their Faces não é satisfatório, sendo considerado "uma caricatura" por Ian Jeffrey. O termo "caricatura" pode parecer demasiado forte, 
mas o autor lembra que a fotógrafa se entrega a uma visão irônica de seus modelos, apresentando pessoas dissimuladas, desanimadas, ingênuas ou trapaceiras (JEFFREY, 1981: 168).

Bem diferente é a atitude de Lange e Evans. Autora da imagem-símbolo da Grande Depressão - Mãe Migrante, Nipoma, Califórnia (1936) -, Lange acreditava que a evidência visual fornecida pela fotografia tinha a capacidade de transmitir a crise vivida pela sociedade naquele momento. Imbuída de um profundo senso de justiça social, engaja-se na produção de imagens sugestivas, repletas de respeito pelo modelo e portadoras, não raro, de uma visão amarga da realidade representada. É o que demonstra Desempregado na Beira do Campo de Ervilhas, Vale Imperial, Califórnia (1937), marcada pela indiferenciação entre a terra e o rosto e a camisa do agricultor, de maneira a evidenciar o que ela e Taylor denominavam "erosão humana” (DYER, 2008: 115). Lange não hesita em colocar sua anterior experiência de retratista a serviço de uma visão penetrante dos modelos. A capacidade de ir além das aparências, que motiva sua contratação por Stryker, está presente tanto nas tomadas em ângulo inferior, que dão um aspecto monumental à composição, quanto na importância conferida à expressão e à gestualidade das pessoas retratadas.

O patos humanista que emana das imagens de Lange está, ao contrário, ausente das fotografias de Evans. Sua indiferença para com as implicações sociais das campanhas da FSA manifesta-se de imediato na documentação realizada na Virgínia Ocidental e na Pensilvânia (junho, julho e novembro de 1935). Nela, Evans persegue seu interesse particular pela serialização, fotografando monumentos públicos, igrejas e cemitérios. Nos trabalhos posteriores feitos para a Seção Histórica (entre os quais o registro das cheias ocorridas no Arkansas e no Tennessee em fevereiro de 1937), sua abordagem distanciada do referente pontua retratos, tomadas de monumentos, vistas urbanas, interiores, flagrantes de cartazes e letreiros, igualmente caracterizados por uma suspensão temporal e, frequentemente, por um senso de melancolia, alheios aos objetivos propagandísticos de Stryker e a seus roteiros pormenorizados.

Interessado nos aspectos vernáculos e irredutíveis às tipologias modernas das culturas locais, Evans dedica uma atenção particular aos signos e à história, deixando de lado um dos tópicos mais explorados pela fotografia norte-americana - a natureza - (CHEVRIER, 2007: 263), em imagens dominadas pelo anonimato, pela simetria e pelo equilíbrio da composição. Definindo-as "enciclopédicas", Jeffrey detecta nelas verdadeiros inventários da vida das pequenas comunidades, nas quais nada é idêntico, em virtude da atenção que o fotógrafo dispensava aos detalhes (JEFFREY, 1981: 172-174).

O recenseamento da realidade norte-americana levado a cabo nos trabalhos para a FSA e na reportagem para Fortune ganha uma organização particular no catálogo da exposição Fotografias Americanas (1938), considerado o primeiro livro fotográfico moderno por Gilles Mora e John Hill. Dividido em duas partes - retratos da América e retratos dos americanos -, o catálogo é concebido por Evans como um fluxo contínuo de imagens, que o leitor deveria apreciar a partir do ritmo da apresentação. As legendas são relegadas ao final da publicaçáo, pois o fotógrafo desejava que suas imagens fossem visualizadas de maneira autônoma, na condição de composiçóes autossuficientes (MORA e HILL, 2004: 161).

$\mathrm{O}$ distanciamento entre imagem e legenda e o abandono de uma ordem cronológica rigorosa não são os únicos índices da busca de uma fotografia au- 


\section{Artigos \& Ensaios}

2 - O título dado por Chassey é Mulher de Meeiro de Algodão do Alabama. Ele foi revisto a partir do livro de Gilles Mora e John Hill, que pesquisaram detaIhadamente a exposição "Fotografias americanas" e seu catálogo. tônoma por Evans. Como assinala Éric de Chassey, o retrato de Annie Mae Gudger, publicado em Elogiemos os Homens Ilustres, é um exemplo eloquente de fotografia autossuficiente. Dois elementos contribuem para isso. O primeiro diz respeito à tomada, que integra o modelo numa imagem plana (e, logo, moderna), na qual são igualmente determinantes seus traços fisionômicos (sobretudo o queixo quadrado), os motivos e as pregas do tecido e os veios da madeira da parede. O segundo é localizado pelo autor nas quatro versôes da imagem, diferentes entre si pela expressão da boca e pela inclinação do rosto, e nos títulos que foram sendo dados. Apresentada como Mulher de Lavrador Arrendatário do Alabama [2] em Fotografias Americanas, é reproduzida sem legenda em Elogiemos os Homens Ilustres, até receber o título atual: Allie Mae Burroughs, Condado de Hale, Alabama. Os diferentes títulos e versóes da fotografia seriam índices de sua autossuficiência em relação ao referente. Se este não é diminuído, é, porém, neutralizado no momento da visão, ao ser remetido à experiência de cada observador antes de ganhar uma eventual densidade a partir das informaçóes dadas pelo título (CHASSEY, 2006: 69-70).

Chassey faz referência a outros dois exemplos de imagens autossuficientes no interior de Elogiemos os Homens Ilustres. Na primeira delas - Squincky Burroughs Dormindo -, em virtude da adoção do ângulo superior, Evans transforma os objetos numa composição geométrica, jogando com as linhas oscilantes do piso de madeira. Desse modo, o fotógrafo reconduz a imagem a um plano único, procedimento que seguirá também em Instantâneos, Casa da Família Tingle, a qual se resume a duas fotografias contíguas, pregadas numa parede de madeira (CHASSEY, 2006: 89).

O fato de parte das imagens de Evans ser caracterizada pela planaridade, própria da arte moderna, não deve fazer perder de vista outro aspecto determinante de sua poética: o interesse pela organização de sequências, nas quais nenhuma fotografia isolada se sobrepóe ao conjunto. Essa estratégia, que já fora utilizada na mostra "Fotografias americanas", estruturada em cinco sequências arquitetura, cartazes e letreiros, edifícios, pessoas e paisagens - (MORA e HILL, 2004: 160) e no catálogo homônimo, é retomada em Elogiemos os Homens Ilustres.

A figura de um senhorio abre a sequência do condado de Hale, sendo seguida por retratos da família Gudger/Burroughs, por algumas tomadas do interior de sua casa e pela inquietante fotografia da criança dormindo no chão, coberta por um lençol que mais parece uma mortalha. A mesma lógica de apresentação rege as microsséries dedicadas aos Fields/Woods e aos Ricketts/Tingle: Evans começa seu recenseamento com retratos para adentrar logo depois na intimidade dos lares, representada, no segundo caso, apenas pelas fotografias pregadas na parede. As três últimas imagens, caracterizadas pela ausência humana, por um senso de vazio e pela suspensão de toda atividade, confrontam o observador com aspectos urbanos do condado de Hale e com um entorno degradado e em visível estado de abandono, até mesmo no caso da prefeitura. É possível pensar que as duas últimas fotografias centradas em elementos arquitetônicos tenham sido concebidas como um contraponto à modesta casa de madeira que encerra a microssequência dedicada à família Fields, da qual se desprende uma sensação de solidez.

A busca de uma imagem neutra e de uma abordagem não emotiva do tema não significa que o conjunto do Alabama não seja portador de uma visão crítica dos Estados Unidos da Depressão. A sensação de esqualidez embutida 
nas sequências transforma-as em imagens eloquentes de um tempo de crise, sem que Evans seja obrigado a lançar mão de uma série de recursos retóricos, tão caros à vertente humanista da fotografia. Ao apresentar os agricultores em seus contextos específicos, ao adentrar em suas residências e ao destacar nesses interiores alguns artefatos dotados de uma história própria - prateleiras e paredes nas quais se destacam objetos variados e, sobretudo, os instantâneos guardados pelos Ricketts -, o fotógrafo não deixa de subscrever os requisitos, eivados de um viés irônico, que Agee havia estabelecido para a reportagem. É possível detectar nas fotografias tanto a presença da "percepção da seriedade e do mistério do tema" quanto a consciência da "responsabilidade humana" (AGEE, 2008: 26), da qual os dois autores estavam investidos em virtude da natureza do próprio trabalho. Tudo está inserido num contexto no conjunto do Alabama. As pessoas são retratadas em suas residências. As casas apresentam-se não como símbolos, mas como imagens-signos, como documentos-monumentos, para usarmos, de maneira ampliada, as observações de Jean-François Chevrier sobre as vistas urbanas de Evans (CHEVRIER, 2007: 263-264).

$\mathrm{Na}$ segunda edição do livro realizada em 1960, a ideia de contexto é ampliada, embora nem todas as sessenta e duas fotografias utilizadas correspondam ao conjunto do Alabama. A casa de Gudger/Burroughs ganha um destaque maior; há referências explícitas ao trabalho, enfeixadas num par de botinas largadas no chão e numa figura feminina colhendo algodão. $\mathrm{O}$ mesmo acontece com as tomadas de Fields/Woods e de Ricketts/Tingle. Do primeiro há um retrato posado no campo de algodáo, além da imagem de uma pequena horta. As referências ao interior da residência da segunda família são ampliadas, indo além dos dois instantâneos de 1941 e incluindo a imagem de uma parede que, na primeira edição, integrava a microssequência de Fields/Woods.

Os aspectos urbanos e arquitetônicos recebem um reforço considerável. Se, em alguns momentos, criam um contraponto com a miséria, que é o traço distintivo da vida das três famílias, na maioria das vezes, Evans detém-se em construções precárias, tortas, em estado de ruína, quer se trate de pequenas vendas, quer se trate de moradias. Nenhum traço relevante desse microcosmo escapa da câmera de Evans. Escolas rurais, o posto de correio, uma estação ferroviária, uma residência senhorial abandonada, homens jogando conversa fora, uma parelha de cavalos, um cartaz publicitário compóem um cenário melancólico, visto de maneira fria e desapaixonada pelo fotógrafo. A microssequência encerra-se com um túmulo e com um galho com cabaças, que acentuam a sensação de desolação do conjunto, dando a ver o viés crítico que estava na base das fotografias do condado de Hale.

Do mesmo modo que na série dedicada à arquitetura vitoriana, Evans adota quase sempre uma posição frontal em relação ao tema para melhor sublinhar a impessoalidade do próprio ponto de vista e a determinação de captar imagens nítidas, bem definidas e facilmente decodificáveis. Embora esteja interessado primordialmente em formas, não descuida do contexto em que as edificaçóes estão inseridas. Chega a conceder espaço à natureza, criando algumas interaçóes entre edifícios e vegetação, que parecem acentuar a pobreza e a mediocridade da arquitetura popular. Mesmo quando lida com exemplares de uma concepção mais qualitativa, opta por tomadas que privilegiam uma visão de conjunto, sem por isso negligenciar a presença de detalhes significativos. Contribuem para isso o tipo de iluminação escolhida, que realça as formas arquitetônicas com uma luz 
direta, e a presença de poucas sombras.

É significativo que nas duas ediçóes de Elogiemos os Homens Ilustres a sequência se inicie com a figura de um proprietário. Se o aspecto limpo e arrumado do homem gera um contraste com boa parte das figuras humanas apresentadas a seguir, náo se pode deixar de assinalar que o ponto de vista frontal adotado pelo fotógrafo acaba por reconduzir a imagem a um universo partilhado com os agricultores, pouco importando a posiçáo ocupada na escala social. Se, como observa Pierre Bourdieu, o retrato frontal permite que o modelo adote uma postura cerimonial, oferecendo ao outro uma imagem de si "preparada de antemáo" e impondo as normas de sua percepção (BOURDIEU, 1979: 129), é também importante lembrar que a frontalidade absoluta, atributo de uma cultura popular e campesina, é refutada por aristocracia e burguesia, que preferem adotar uma pose lateral como sinal de distinção.

Em vários momentos, os modelos humildes de Evans assumem poses laterais, o que demonstra que o fotógrafo, depois da atitude agressiva do primeiro encontro, estabelece uma negociação com eles sobre o melhor modo de representaçáo. O convívio dessas duas possibilidades e a colaboração dos modelos na determinação do que era conveniente mostrar de si têm a ver com o título que será dado ao livro. Elogiemos os Homens Ilustres tem como fonte de inspiração o capítulo 44, versículos 1 a 14, do "Eclesiástico". Dedicado à Sabedoria, o livro, que integra o Velho Testamento, é, em sua décima parte, um hino de louvor aos patriarcas, de Adão até Simão. Ao optar por esse título, Agee demonstra desejar conferir uma dignidade ímpar a pessoas que não teriam como deixar sua marca na história, por não poderem ombrear com aqueles que, designados por Deus, contribuíram para o bem da humanidade e da sociedade. O título escolhido é, pois, um recurso retórico de que o escritor se serve para exaltar a dignidade dos mais pobres entre os pobres e para legar seu testemunho de vida à posteridade. Apesar de seu estilo distanciado e desapaixonado, Evans não fica atrás nessa tarefa, ao fazer vir à tona a dimensão psicológica do grupo de agricultores.

Mesmo vestindo roupas pobres, manchadas ou, até mesmo, sujas, os modelos do Alabama são retratados com respeito, são apresentados como figuras dotadas de uma grande dignidade por conseguirem suportar uma condição tão adversa. Se duas leituras pontuam o livro - uma escrita cumulativa que, em vários momentos, dá a impressáo de estar fotografando o objeto a partir de múltiplos pontos de vista, e uma visualidade enxuta e essencial -, é, porém, inegável a justeza da observação de Agee sobre o duplo estatuto de independência e reciprocidade entre as partes. É difícil ler as páginas de Agee sem querer voltar atrás, em busca daquelas imagens que ajudam a conferir um aspecto mais realista, mais palpável às digressóes e às longas descriçōes que são uma parte determinante do relato. Delas emerge um perfil afiado das três famílias, das casas que habitam, de sua parca mobília e dos poucos objetos de uso cotidiano, dos animais que possuem, da terra que lavram, de diferentes odores, mas não resta dúvida de que as imagens sintéticas de Evans permitem apanhar, de um só golpe, uma situaçáo que, por vezes, desnorteia o leitor com sua infinita riqueza de detalhes, fazendo-lhe perder de vista uma ideia de conjunto.

Evans será poupado das críticas que atingem o livro em 1941. O que estava em jogo, naquele momento, era a escrita experimental de Agee, que faz 
com que a crítica não perceba um dos objetivos centrais do livro: ensaiar uma reflexão sobre dois instrumentos de criação, para além da dimensão de uma simples reportagem ou de um frio estudo antropológico. Em busca de uma "noção de 'realidade' e de 'valores", voltada às "formas artísticas algo novas [...] de que as câmeras de instantâneos e de filmagem são os instrumentos e símbolos mais vigorosos", Agee propugna "uma forma de ver a existência" baseada

em uma interseção da física astronômica, da geologia, e (sem excluir a psicologia) da antropologia, conhecida e comentada não em termos científicos, mas humanos. Nada que surja dessa interseção pode sequer correr o risco da insignificância: tudo é proporcionalmente tremendamente significante quando se aproxima em nossa percepçáo, simultaneamente, de seus próprios termos singulares e de seu ramificado parentesco e provável identificação oculta com todas as coisas (AGEE, 2009: 234-235).

As fotografias de Evans participam, de maneira autônoma e cooperativa a um só tempo, desse objetivo, ajudando a configurar um quadro da América da Depressão destituído de artifícios e de efeitos sentimentais e, por isso mesmo, mais contundente em sua extrema economia formal. A imposiçáo de uma ordem estética ao caos da realidade social, que causara os protestos de Stryker durante sua colaboração com a Seção Histórica (MORA e HILL, 2004: 134), é potencializada no conjunto do Alabama. Há sempre um desígnio estético nas composiçóes do fotógrafo, que faz com que suas imagens sejam, ao mesmo tempo, documentos e obras de arte independentes. Essa independência voluntariamente buscada, evidenciada pela pose dos modelos e pelos ângulos escolhidos, é, afinal, o alicerce da construção documental, posto que Evans náo escamoteia o próprio ponto de vista e, logo, a natureza ambígua e complexa do documento fotográfico. Se ele não faz propaganda, não apresenta tampouco um registro descompromissado. Um sentimento de simpatia pelos modelos e por seu ambiente de vida emana dessas imagens, transformando-as em preciosas fontes de uma memória visual que, embora alicerçada no distanciamento e na neutralidade, não perde de vista a dimensão humana de uma experiência que parece ter calado fundo no fotógrafo.

\section{REFERENCLAS BIBLIOGRÁFICAS}

AGEE, James. Elogiemos os Homens Ilustres. Trad. Caetano Waldrigues Galindo. São Paulo: Companhia das Letras, 2009.

BOURDIEU, Pierre. "La definición social de la fotografia". In: BOURDIEU, Pierre (org.). La Fotografía: un Arte Intermedio. México: Editorial Nueva Imagen, 1979, p. 107-148.

CAMPANY, David. "Une intervention récalcitrante: les pages de Walker Evans”. Études Photographiques, Paris, n. 27, maio 2011, p. 86-110.

CHASSEY, Éric de. Platitudes: une Histoire de la Photographie Plate. Paris: Gallimard, 2006.

. "Les photographies d'architecture victorienne de Walker Evans et l'invention du style documentaire". Les Cahiers du Mnam, Paris, n. 92, verão 2005, p. 
74-93.

CHEVRIER, Jean-François. "Walker Evans/Dan Graham: doble lectura”. In: La Fotografía entre las Bellas Artes y los Medios de Comunicación. Barcelona: Gustavo Gili, 2007, p. 229-273.

DYER, Geoff. O Instante Contínu: uma História Particular da Fotografia. Trad. Donaldson M. Garschagen. São Paulo: Companhia das Letras: 2008.

EVANS, Walker. "The reappearance of photography”. In: ROSENHEIM, Jeff L. e EKLUND, Douglas (org.). Unclassified: a Walker Evans Anthology. Zurique/Berlim/Nova York: Scalo; Nova York: The Metropolitan Museum of Art, 2000, p. 80-84.

HAGEN, Charles. "Elements à photographier pour rendre compte de la réalité américaine”. In: Centre National de la Photographie (org.). Amérique. Les Années Noires: Farm Security Administration/1935-1942. Paris: Centre National de la Photographie, 1983, s. p.

JEFFREY, Ian. Photography: a Concise History. Nova York/Toronto: Oxford University Press, 1981.

MORA, Gilles e HILL, John T. Walker Evans: the Hungry Eye. Londres: Thames \& Hudson, 2004.

SUZUKI Jr., Matinas. "O algodão agridoce”. In: AGEE, James. Elogiemos os Homens Ilustres. Trad. Caetano Waldrigues Galindo. São Paulo: Companhia das Letras, 2009, p. 433-454. 